\title{
Comparison of resection site of standardized laparoscopic hepatic tumor resection
}

\author{
Yoshihiro Inoue ${ }^{1}$, Masatsugu Ishii ${ }^{1}$, Yusuke Tsuchimoto ${ }^{2}$, Shinsuke Masubuchi ${ }^{1}$, Masashi Yamamoto ${ }^{1}$, Akira Asai $^{2}$, \\ Shinya Fukunishi ${ }^{2}$, Fumitoshi Hirokawa ${ }^{1}$, Kazuhide Higuchi' ${ }^{2}$, Kazuhisa Uchiyama ${ }^{1}$ \\ ${ }^{1}$ Department of General and Gastroenterological Surgery, Osaka Medical College Hospital, Osaka, Japan \\ ${ }^{2}$ The Second Department of Internal Medicine, Osaka Medical College Hospital, Osaka, Japan
}

Videosurgery Miniinv 2018; 13 (3): 333-341

DOI: https://doi.org/10.5114/wiitm.2018.75866

\begin{abstract}
Introduction: The degree of difficulty in laparoscopic hepatic resection (LHR) was higher in tumors involving the suprahepatic segments than other sites. However, thanks to surgical instruments and procedures being improved and standardized, LHR can be performed safely in all regions.

Aim: We report our standardized surgical techniques and outcomes in a series of patients undergoing LHR in our hospital and analyze the surgical outcomes, particularly with regard to the site of resection.

Material and methods: We retrospectively analyzed data from 238 patients who underwent standardized laparoscopic partial hepatic resection between 2010 and 2017. In standardized LHR, the operator formed a triangle with the laparoscope in the center, maintaining a co-axial position by changing the port where the laparoscope was inserted.

Results: Operative time for the resection of tumors of the right hepatic lobe was $202 \pm 92$ min and $140 \pm 104$ min for tumors of the left hepatic lobe ( $p=0.0024)$; intraoperative blood loss was $80 \pm 170 \mathrm{ml}$ and $19 \pm 127 \mathrm{ml}$, respectively $(p=0.0016)$. No differences were found in the surgical outcomes between the various segments of the right hepatic lobe. In the left hepatic lobe, operative time was significantly shorter with laparoscopic tumor resection in segment III $(p=0.0023)$.

Conclusions: During standardized LHR, a better field of vision with the greater ease can be established during resection of the left hepatic lobe compared to that of the right hepatic lobe. Nonetheless, LHR of the right lobe can be performed safely using various surgical instruments and techniques.
\end{abstract}

Key words: resection site, standardized laparoscopic hepatic resection, co-axial position, triangular formation, intercostal port, occlusion of the hepatic inflow.

\section{Introduction}

The minimally invasive nature of laparoscopic surgery along with significant technical improvements over the past 20 years has made laparoscopic surgery a viable alternative to conventional open surgery in many fields, including gastrointestinal surgery [1]. Currently, various hepatic procedures, including partial hepatic resection for hepatocellular carcinoma or metastatic liver cancer, are conducted with laparoscopic surgery [2]. Previous studies have shown that laparoscopic partial hepatic resection demonstrated significantly improved outcomes compared to those seen with open partial hepatic resection, including a decrease in perioperative bleeding, a reduction in the incidence of surgical site

\section{Address for correspondence}

Yoshihiro Inoue MD, Department of General and Gastroenterological Surgery, Osaka Medical College Hospital, 2-7 Daigaku-machi, Takatsuki City, Osaka 569-8686, Japan, phone: +81 072 (683) 1221, fax: +81 072685 2057, e-mail: sur129@osaka-med.ac.jp 
infection (SSI), and a reduced postoperative inflammatory reaction $[3,4]$. These improved outcomes were the result of advances and improvements in surgical procedures and instrumentation used for laparoscopic hepatic resection.

Laparoscopic hepatic resection was originally used for tumor resections in the marginal sites of the subhepatic region but is now indicated for resection of deeper lesions. At the Second International Consensus Conference on Laparoscopic Hepatic Resection held in Morioka in 2014, a difficulty scoring system was advocated to determine the degree of difficulty of laparoscopic hepatic resection based on preoperative information for each patient. Ban et al. validated the degree of difficulty scores for use in laparoscopic liver resection and reported a higher degree of difficulty for right hepatic lobe tumors, especially those tumors involving the suprahepatic segments (segments VII and VIII) compared with that seen with other laparoscopic hepatic tumor resection sites [5]. Nonetheless, in that study, they found that laparoscopic hepatic resection for tumors in the suprahepatic segment had been successfully performed in many institutions. Improvements in surgical instrumentation and techniques were responsible for the ability to safely resect tumors in hepatic areas characterized by a high degree of difficulty.

\section{Aim}

Here, we describe the application of these standardized surgical techniques and outcomes in a series of patients undergoing laparoscopic partial hepatic resection in our hospital. We also analyze the surgical outcomes in these patients, particularly with regard to the site of resection.

\section{Material and methods}

\section{Patient population and selection}

Laparoscopic hepatic resection (LHR) was introduced to our hospital in 1998, and by 2010 we had developed a standard procedure for laparoscopic hepatic resection. This study included patients who have undergone laparoscopic hepatic resection since 2010, when standardization of the surgical procedure was established.

Between February 17, 2010 and February 27, 2017, we conducted laparoscopic partial hepatic resection for liver tumors on 238 consecutive patients at Osaka Medical College Hospital in Takatsuki City, Japan. All patients were fully informed of the study design according to the Ethics Committee on Clinical Investigation of Osaka Medical College Hospital (No. 1828 and 1997) and provided written informed consent. A tumor size $<5 \mathrm{~cm}$ was the main criterion for LHR; tumor number and tumor location are not criteria. However, patients with portal or hepatic vein involvement or invasion of adjacent organs were not considered candidates for LHR.

Criteria to convert laparoscopic to open hepatic resection were as follows: (1) if the liver stumps of both preserved and resected sides could not be adequately expanded, (2) if intraoperative bleeding could not be controlled, (3) if blood loss exceeded $500 \mathrm{ml}$, (4) if the total time of the Pringle maneuver (hepatic blood flow occlusion) exceeded $120 \mathrm{~min}$, and (5) if intraoperative bile leakage could not be controlled during surgery.

\section{Surgical procedure}

In this series, all patients underwent potentially curative hepatic resection with complete removal of the gross tumor with negative macroscopic margins. All procedures during the study period were performed by one of three experienced hepatobiliary surgeons ( $\mathrm{Yl}, \mathrm{FH}, \mathrm{KU})$.

The detailed laparoscopic surgical technique routinely used in our department has been described in previous reports $[3,6,7]$. Briefly, patients undergoing resection of a right hepatic lobe tumor were placed in a left lateral recumbent position. Patients undergoing resection of a left hepatic lobe tumor were placed in a supine position. A continuous carbon dioxide $\left(\mathrm{CO}_{2}\right)$ pneumoperitoneum was induced at a pressure limit of $12 \mathrm{~mm} \mathrm{Hg}$ and a flow of $6 \mathrm{l} / \mathrm{min}$ to decrease the risk of gas embolism. Four 5- to 12-mm trocars and a 45-degree laparoscope (1588 AIM; Stryker Japan K.K., Tokyo, Japan) were fixed. For patients undergoing resection of a cephalad tumor involving the right hepatic lobe (segments VII and VIII), an intercostal port was inserted (two ports for segment VII; one port for segment VIII) (Photo 1).

Mobilization of the liver was begun; the lateral hepatic attachment and the triangular ligament were divided using a harmonic scalpel (from 2009 to 2013) (Ultracision; Ethicon Endosurgery, Tokyo, Japan) or the Surgical Tissue Management System (since 2014) (Thunderbeat; Olympus Inc., Tokyo, Japan) after the round and falciform ligaments were 

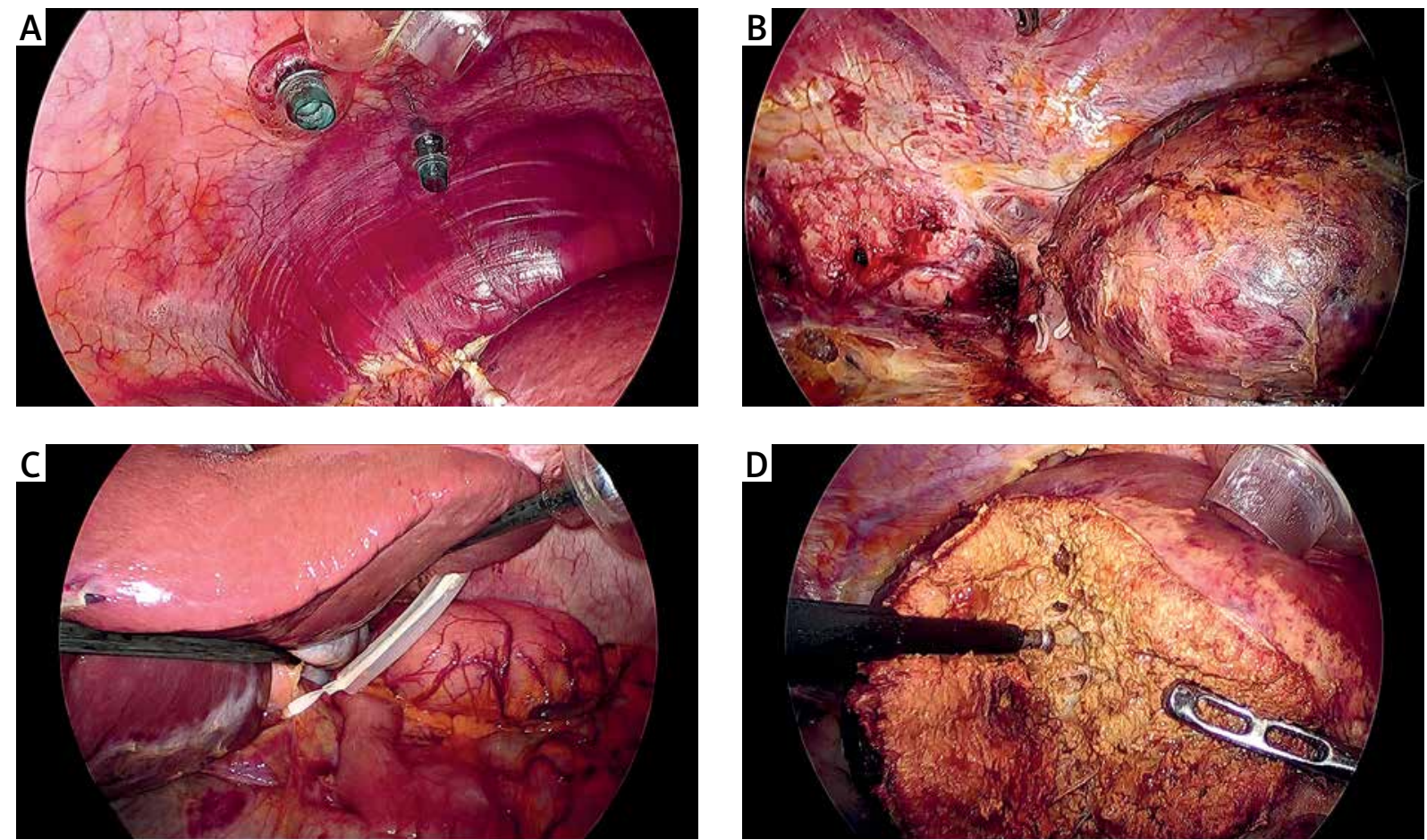

Photo 1. Laparoscopic hepatic resection from intercostal port. A - We placed two 5-mm intercostal ports with balloons between the seventh and the tenth intercostal spaces. B - Lateral view: by inserting the laparoscope through the intercostal port, we are able to view the liver from the outside, with the area from the root area of the right hepatic vein to the entire length of the inferior vena cava in full vision. C - An extracorporeal Pringle maneuver was performed. Blood flow was occluded by clamping a vascular occlusion tube (Vessel-Clude; Argon Medical Devices Inc., United States) from outside the body. Intermittent clamping was applied, with 15-minute clamping and 5-minute release periods. $\mathbf{D}$ - The operator takes the co-axial position, and maintains the triangular formation with the laparoscope in the center. By doing so, the operator is able to prevent loss of space recognition ability, and control the right and the left forceps towards the target organ

dissected. This dissection was typically carried up to the diaphragm, allowing more effective mobilization of the liver.

Next, an extracorporeal Pringle maneuver was performed. Blood flow was occluded by clamping a vascular occlusion tube (Vessel-Clude; Argon Medical Devices Inc., United States) from outside the body. Intermittent clamping was applied, with 15-minute clamping and 5-minute release periods.

By changing the port the where the laparoscope was inserted, the operator formed a triangle with the laparoscope in the center, placing the operator, target area, and the laparoscopic monitor in a straight line, maintaining a co-axial position. Central venous pressure (CVP) was maintained at 3$5 \mathrm{~mm} \mathrm{Hg}$ during parenchymal transection. Parenchymal transection was achieved using the Sonop 5000 ultrasonic dissector (Hitachi Aloka Medical, Ltd.) and the Thunderbeat during the extracorporeal Pringle maneuver. Small vessels were ligated or coagulated using a soft-coagulation system. Intraparenchymal control of the major vessels was achieved with clips, whereas biliary and vascular radicle division was obtained with clips or stapling devices. The resected, undivided specimen was placed in a plastic retrieval bag and removed through the slightly enlarged periumbilical incision.

\section{Preoperative factors}

Data examined included preoperative factors, surgical factors, and pathological factors. Preoperative factors investigated were age, sex, viral infection status, serum aspartate aminotransferase (AST) level, serum alanine aminotransferase (ALT) level, platelet 
count, serum albumin level, total bilirubin level, prothrombin time (PT), Child-Pugh classification, and indocyanine green retention rate at 15 min (ICG-R15).

\section{Surgical and pathological factors}

Surgical factors included conversion rate, surgical duration, intraoperative blood loss, and blood transfusion requirements. Pathological factors evaluated included the size of the largest tumor, number of tumors, and surgical margin status. "R" classification denoted the absence or presence of residual tumor after surgery [8]. R0 resection refers to excision of the tumor in one piece without violating the tumor plane or achieving negative margins after sequential re-excision of the involved margins. R1 resection involves a microscopically positive margin anywhere, and $R 2$ resection involves a macroscopically positive margin(s) with visible tumor.

\section{Postoperative evaluation}

The following parameters were evaluated: transfusion rate, pathological margins, postoperative com- plications, 30-day mortality, and hospital stay. Morbidity was graded according to Clavien's classification $[9,10]$. SSIs were defined according to the Centers for Disease Control and Prevention's (CDC) National Nosocomial Infection Surveillance (NNIS) system [11].

\section{Statistical analysis}

Continuous variables were expressed as the median \pm standard deviation (SD). Univariate analysis results were compared by Student's $t$ and $\chi^{2}$ tests, the Mann-Whitney $U$ test, the Wilcoxon signed-rank test, or Fisher's exact test, as appropriate. Multivariate analyses were performed by Cox proportional hazards regression. Values of $p<0.05$ were considered significant. All statistical analyses were performed using JMP version 12 (SAS Institute, Inc., Cary, NC, USA).

\section{Results}

\section{Patient demographics}

Table I shows the patient characteristics and surgical results by group. The operative times were

Table I. Demographic data of patients who underwent laparoscopic hepatic resection

\begin{tabular}{|c|c|c|c|c|c|c|c|c|c|}
\hline \multirow[t]{2}{*}{ Parameter } & \multicolumn{8}{|c|}{ Segment } & \multirow[t]{2}{*}{$P$-value } \\
\hline & I & II & III & IV & V & VI & VII & VIII & \\
\hline Number & 3 & 13 & 32 & 38 & 38 & 39 & 37 & 38 & \\
\hline $\begin{array}{l}\text { Conversion to } \\
\text { open procedure }\end{array}$ & 1 & 0 & 1 & 4 & 3 & 2 & 4 & 5 & 0.2312 \\
\hline $\begin{array}{l}\text { Completed } \\
\text { laparoscopic } \\
\text { surgery }\end{array}$ & 2 & 13 & 31 & 34 & 35 & 37 & 33 & 33 & \\
\hline Age [years] & $\begin{array}{c}64 \\
(61-66)\end{array}$ & $\begin{array}{c}71 \\
(25-83)\end{array}$ & $\begin{array}{c}68 \\
(13-87)\end{array}$ & $\begin{array}{c}67 \\
(28-80)\end{array}$ & $\begin{array}{c}72 \\
(46-85)\end{array}$ & $\begin{array}{c}67 \\
(29-86)\end{array}$ & $\begin{array}{c}67 \\
(39-80)\end{array}$ & $\begin{array}{c}72 \\
(41-80)\end{array}$ & 0.6969 \\
\hline $\begin{array}{l}\text { Sex } \\
\text { (male: female) }\end{array}$ & $1: 1$ & $9: 4$ & $15: 16$ & $24: 10$ & $26: 9$ & $21: 16$ & $17: 16$ & $21: 12$ & 0.3242 \\
\hline Pathology: & & & & & & & & & 0.1196 \\
\hline $\mathrm{HCC} / \mathrm{ICC}$ & 2 & 8 & 11 & 19 & 20 & 16 & 10 & 16 & \\
\hline Meta/Others & 0 & 5 & 20 & 15 & 15 & 21 & 23 & 17 & \\
\hline $\begin{array}{l}\text { Child/Pugh } \\
\text { grading (A/B) }\end{array}$ & $2 / 0$ & $12 / 0$ & $28 / 1$ & $34 / 0$ & $33 / 1$ & $34 / 2$ & $33 / 0$ & $32 / 0$ & 0.6141 \\
\hline $\begin{array}{l}\text { Number of } \\
\text { tumors }\end{array}$ & $1(1-2)$ & $1(1-3)$ & $1(1-4)$ & $1(1-3)$ & $1(1-2)$ & $1(1-5)$ & $1(1-4)$ & $1(1-3)$ & 0.6222 \\
\hline $\begin{array}{l}\text { Size of largest } \\
\text { tumor (range) } \\
{[\mathrm{cm}]}\end{array}$ & $\begin{array}{c}2.4 \\
(2.0-2.8)\end{array}$ & $\begin{array}{c}2.3 \\
(1.0-6.0)\end{array}$ & $\begin{array}{c}1.7 \\
(0.8-4.5)\end{array}$ & $\begin{array}{c}2.3 \\
(0.8-4.1)\end{array}$ & $\begin{array}{c}2.4 \\
(0.7-3.4)\end{array}$ & $\begin{array}{c}2.4 \\
(1.0-4.7)\end{array}$ & $\begin{array}{c}2.5 \\
(0.9-4.0)\end{array}$ & $\begin{array}{c}2.5 \\
(1.3-4.7)\end{array}$ & 0.7843 \\
\hline
\end{tabular}

HCC - hepatocellular carcinoma, ICC - intrahepatic cholangiocellular carcinoma, Meta - metastasis. 
$202 \pm 92$ min and $140 \pm 104$ min for tumors involving the right hepatic lobe and the left hepatic lobe, respectively. This difference was statistically significant ( $p=0.0024)$. Intraoperative blood loss was significantly different, $80 \pm 170 \mathrm{ml}$ and $19 \pm 127 \mathrm{ml}$ for the right and left lobes, respectively $(p=0.0016)$. There were no significant differences in postoperative intravenous feeding days ( $p=0.9181)$, postoperative hospitalization days ( $p=0.8970)$, or complication rates ( $p=0.2976)$, between the right hepatic and left hepatic lobe tumor resection groups (Table II).

For tumors of the left hepatic lobe (segments II, III, and IV), there was no significant difference in postoperative course (Table III); however, operative time was significantly shorter in laparoscopic hepatic resections of segment III ( $p=0.0023$, Figures 1,2$)$. For tumors of the right hepatic lobe (segments V, VI, VII, and VIII), there was no significant difference in surgical outcomes between the various segments (Table IV).

\section{Risk factors for conversion from laparoscopic to open hepatic resection}

Perioperative factors were compared between patients with and without conversion to open hepatic resection. Eighteen factors were examined, including patient factors, tumor factors, and operative factors.
Of the factors analyzed, hepatitis $C$ viral infection $(p=0.0381)$, pathology $(p=0.0349)$, operative time $(p=0.0148)$, and blood loss $(p<0.0001)$ were found to be significant risk factors for conversion to open hepatic resection.

Duration of surgery was significantly longer in patients with conversion to open hepatic resection than in those without conversion $(223 \pm 22$ vs. $180 \pm 7 \mathrm{~min}$, respectively; $p=0.0148)$. Receiver-operator characteristic (ROC) curve analysis indicated that the optimal cutoff value for operative time was $195.0 \mathrm{~min}$, yielding $85.0 \%$ sensitivity and $57.6 \%$ specificity for conversion to open hepatic resection.

Estimated blood loss was significantly greater in patients with conversion to open hepatic resection than in those without conversion $(515 \pm 55$ vs. 50 $\pm 17 \mathrm{ml}$, respectively; $p<0.0001$ ). ROC curve analysis indicated that the optimal cutoff value for operative blood loss was $210.0 \mathrm{ml}$, yielding $80.0 \%$ sensitivity and $84.0 \%$ specificity for conversion to open hepatic resection.

Multivariate analysis demonstrated that estimated blood loss ( $p<0.0001$; odds ratio (OR): 12.295; 95\% confidence interval (Cl): 3.591-51.773) was an independent risk factor for conversion to open hepatic resection (Table $\mathrm{V}$ ).

Table II. Surgical outcomes of patients who underwent laparoscopic hepatic resection

\begin{tabular}{|lccc|}
\hline Parameter & Right lobe & Left lobe & $P$-value \\
\hline Number & 152 & 83 & \\
\hline Conversion to open procedure & $14(9.2 \%)$ & $5(6.0 \%)$ & 0.6299 \\
\hline Completed lap surgery & 138 & 78 & $0.0024^{*}$ \\
\hline Operative time [min] & $202(50-536)$ & $140(40-515)$ & $0.0016^{*}$ \\
\hline Blood loss [ml] & $80(0-950)$ & $19(0-850)$ & 0.6732 \\
\hline Blood transfusion (\%) & $6(4.3 \%)$ & $5(6.0 \%)$ & 0.4231 \\
\hline Surgical margin [mm] & $6(0-20)$ & $5(0-30)$ & 0.1533 \\
\hline Curative resection, RO & $129(93.5 \%)$ & $70(89.7 \%)$ & 0.2976 \\
\hline Complications: & $13(9.4 \%)$ & $4(5.1 \%)$ & 0.8604 \\
\hline Clavien-Dindo classification $>$ IIIA & $6(4.3 \%)$ & $3(3.8 \%)$ & 1.0000 \\
\hline Organ/space SSIs & $1(0.7 \%)$ & $0(0 \%)$ & 0.8970 \\
\hline Hospital mortality & $10(5-124)$ & $9(3-173)$ & \\
\hline Postoperative hospital stay [days] & & & \\
\hline
\end{tabular}

${ }^{*} P<0.05$. Lap - laparoscopic, SSI - surgical site infection. 
Table III. Surgical outcomes of patients who underwent laparoscopic hepatic resection

\begin{tabular}{|lcccc|}
\hline Parameter & II & III & IV & $P$-value \\
\hline Number & 13 & 32 & 38 & 0.2188 \\
\hline Conversion to open procedure & $0(0 \%)$ & $1(3.1 \%)$ & $4(10.5 \%)$ & 34 \\
\hline Completed lap surgery & 13 & 31 & $164(69-515)$ & $0.0023^{*}$ \\
\hline Operative time [min] & $152(43-350)$ & $103(40-276)$ & $50(0-450)$ & 0.0631 \\
\hline Blood loss [ml] & $50(0-850)$ & $0(0-180)$ & $2(5.9 \%)$ & 0.7302 \\
\hline Blood transfusion (\%) & $1(7.7 \%)$ & $2(6.5 \%)$ & $3(0-14)$ & 0.3683 \\
\hline Surgical margin [mm] & $1(0-30)$ & $5(1-20)$ & $31(91.2 \%)$ & 0.1627 \\
\hline Curative resection, R0 & $10(76.9 \%)$ & $29(93.5 \%)$ & $1(2.9 \%)$ & 0.7808 \\
\hline Complications: & $1(7.7 \%)$ & $2(6.5 \%)$ & $0(0 \%)$ & 0.3205 \\
\hline \begin{tabular}{l} 
Clavien-Dindo classification $>$ IIIA \\
\hline Organ/space SSIs
\end{tabular} & $1(7.7 \%)$ & $2(6.5 \%)$ & $0(0 \%)$ & 1.0000 \\
\hline \begin{tabular}{l} 
Hospital mortality \\
\hline Postoperative hospital stay [days]
\end{tabular} & $9(0 \%)$ & $0(0 \%)$ & $9(5-31)$ & 0.6135 \\
\hline
\end{tabular}

${ }^{*} P<0.05$. Lap - laparoscopic, SSI - surgical site infection.

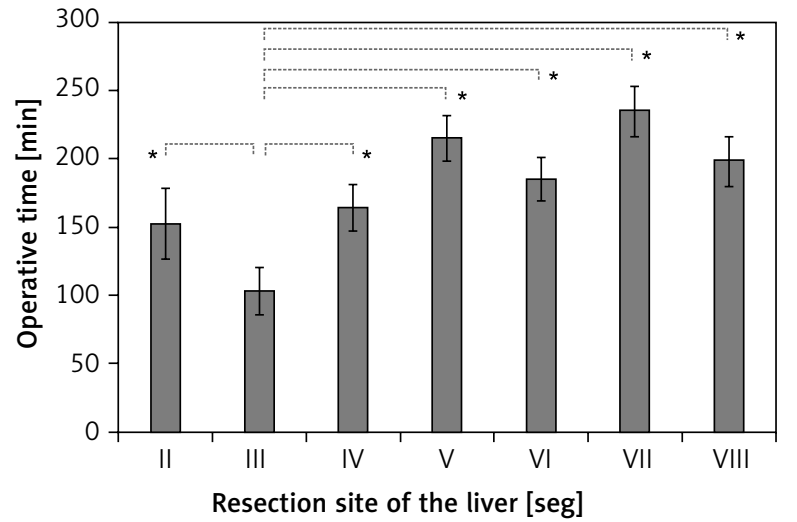

Figure 1. Comparison of each hepatic resection site and operative time. The operative time was significantly shorter in a laparoscopic left hepatic lobe tumor resection than that of the right hepatic lobe $(p=0.0024)$. In particular, the operative time was significantly shorter in the laparoscopic hepatic resection of segment III

${ }^{*} P$-value $<0.05$

\section{Discussion}

The use of laparoscopic hepatic resection has been rapidly adopted because of advantages including the benefits of magnification and view, the effect of pneumoperitoneum pressure on hemostasis, and the low degree of invasiveness. It is accepted

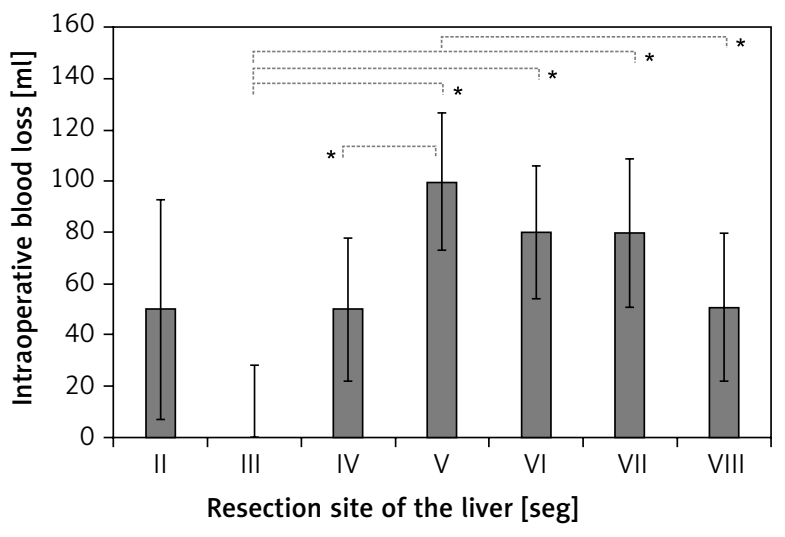

Figure 2. Comparison of each hepatic resection site and intraoperative blood loss. Intraoperative blood loss was $80 \pm 170 \mathrm{ml}$ and $19 \pm 127 \mathrm{ml}$ for the right and left hepatic lobes, respectively; this difference was statistically significant $(p=0.0016)$. In particular, intraoperative blood loss was significantly less in laparoscopic hepatic resection of segment III

${ }^{\star} P$-value $<0.05$.

that laparoscopic partial hepatic resection is superior to laparotomy partial hepatic resection from the viewpoint of invasiveness and cosmesis. However, there remains a concern regarding the safety of laparoscopic hepatic resection in terms of the visual field and operability. When first performed, 
Table IV. Surgical outcomes of patients who underwent laparoscopic hepatic resection

\begin{tabular}{|c|c|c|c|c|c|}
\hline Parameter & $\mathrm{V}$ & VI & VII & VIII & $P$-value \\
\hline Number & 38 & 39 & 37 & 38 & \\
\hline Conversion to open procedure & $3(7.9 \%)$ & $2(5.1 \%)$ & $4(10.8 \%)$ & $5(13.2 \%)$ & 0.5609 \\
\hline Completed lap surgery & 35 & 37 & 33 & 33 & \\
\hline Operative time [min] & $215(99-510)$ & $185(50-455)$ & $235(105-536)$ & $198(95-427)$ & 0.6149 \\
\hline Blood loss [ml] & $100(0-950)$ & $80(0-600)$ & $80(0-550)$ & $51(0-450)$ & 0.3272 \\
\hline Blood transfusion (\%) & $2(5.7 \%)$ & $1(2.7 \%)$ & $1(3.0 \%)$ & $2(6.1 \%)$ & 0.6601 \\
\hline Surgical margin $[\mathrm{mm}]$ & $6(0-18)$ & $7(0-20)$ & $7(0-19)$ & $6(0-15)$ & 0.6589 \\
\hline Curative resection, RO & $32(91.4 \%)$ & $34(91.9 \%)$ & $32(97.0 \%)$ & $31(93.9 \%)$ & 0.6923 \\
\hline \multicolumn{6}{|l|}{ Complications: } \\
\hline Clavien-Dindo classification > IIIA & $5(14.3 \%)$ & $3(8.1 \%)$ & $3(9.1 \%)$ & $2(6.1 \%)$ & 0.7123 \\
\hline Organ/space SSIs & $3(8.6 \%)$ & $1(2.7 \%)$ & $2(6.1 \%)$ & $0(0 \%)$ & 0.3314 \\
\hline Hospital mortality & $1(2.9 \%)$ & $0(0 \%)$ & $0(0 \%)$ & $0(0 \%)$ & 0.5305 \\
\hline Postoperative hospital stay [days] & $10(5-97)$ & $11(5-124)$ & $9(5-18)$ & $9(5-20)$ & 0.1517 \\
\hline
\end{tabular}

Lap - laparoscopic, SSI - surgical site infection.

it was thought that the degree of difficulty in laparoscopic hepatic resection was greater in tumors involving the suprahepatic segments (segments VII and VIII) than that seen with other sites. In these segments, the use of forceps was limited and an adequate field of vision was difficult to establish [5]. However, surgical tools have advanced rapidly, and with these improvements and the standardization of surgical procedures, the outcomes and safety of laparoscopic hepatic resection will continue to improve. This study reports the results depending on hepatic resection sites in standardized laparoscopic partial hepatic resection.

In this study, the surgical outcomes of laparoscopic resection of the left hepatic lobe were better than those seen with resection of tumors of the right hepatic lobe. These results are thought to be influenced by the greater ease in mobilization of the left hepatic lobe, the easy establishment of a field of vision, and the wide area of available working space. In all segments of the left hepatic lobe, a good field of vision can be established by separating the ligamentum teres hepatis, the falciform ligament, the left coronary ligament, and the triangular ligament. This allows mobilization of the left lobe, without restricting the use of forceps during hepatic resection. This is especially true for segment 3 of the left lobe of the liver, where a superior field of vision can be established at the initiation of abdominal cavity observation without further mobilization of the liver.

However, advanced surgical procedures are often required during laparoscopic right hepatic lobe tumor resection. Difficulties in establishing a field of vision and restrictions in the use of forceps during right hepatic lobe laparoscopic resection contribute to the high degree of difficulty for the resection of tumors in the suprahepatic segments (segments VII and VIII). During laparoscopic hepatic resection, the operator stands in alignment with the hepatic resection site and the laparoscopic monitor, to be in a co-axial position and secure triangular formation centering the laparoscope. In this position the operator can prevent impairment of the ability for space perception due to the special posture during laparoscopic hepatic resection and can control the bilateral forceps towards the target organ easily. Based on this approach, one or two intercostal ports were inserted when performing laparoscopic hepatic resection of a tumor in a suprahepatic segment (segments VII and VIII). By inserting the laparoscope in the intercostal port, or in a port located at the rightside lateral region, the entire area from the root of the right hepatic vein to the inferior vena cava can be seen with direct vision. With a lateral approach, tumors involving the suprahepatic segments are separated, while maintaining a co-axial position and triangular formation. Thereby, the separation of the resection 
side and the isolation side can be sufficiently secured. A blind operation is not performed, and the forceps hardly face the isolation side in the tangential projection, which improves the operability.

As noted above, control of bleeding by establishing a good field of vision and maintaining the operability of forceps is the key to safely performing laparoscopic hepatic resection. As Table $V$ shows, multivariate analysis demonstrated that the estimated intraoperative blood loss was associated with a conversion from laparoscopic to open hepatic resection. To reduce the rate of conversion to open resection, venous bleeding can be decreased by elevating the pneumoperitoneum pressure, decreasing the central venous pressure, reducing the ventilatory volume, and reducing the positive end-expiratory pressure [12]. Furthermore, for separation of the liver parenchyma, we interrupted the hepatic inflow of blood in all patients, unless taping of the porta hepatis was difficult because of ad-

Table V. Predictive factors of conversion to open hepatic resection: univariate (A) and multivariate (B) analysis

A

\begin{tabular}{|c|c|c|c|}
\hline Parameter & Complete laparoscopic surgery & Convert to open surgery & $P$-value \\
\hline Number & 218 & 20 & \\
\hline Age [years] & $68(13-79)$ & $72(53-87)$ & 0.8983 \\
\hline Sex (male : female) & $134: 84$ & $13: 7$ & 0.8132 \\
\hline $\mathrm{BMI}\left[\mathrm{kg} / \mathrm{m}^{2}\right]$ & $22.5(15.4-35.3)$ & $22.7(19.2-27.3)$ & 0.9103 \\
\hline Hepatitis B viral infection & $153(70.2 \%)$ & $12(60.0 \%)$ & 0.3115 \\
\hline Hepatitis C viral infection & $162(74.3 \%)$ & $11(55.0 \%)$ & $0.0381^{\star}$ \\
\hline Diabetes mellitus & $55(25.2 \%)$ & $7(35.0 \%)$ & 0.2916 \\
\hline Pathology (HCC/ICC) & $102(46.8 \%)$ & $14(70.0 \%)$ & $0.0349^{*}$ \\
\hline ICG-R15 (\%) & $13.0(2.9-72.2)$ & $16.1(4.3-32.7)$ & 0.7591 \\
\hline Child-Pugh classification (A/B) & $214 / 4$ & $20 / 0$ & 0.5146 \\
\hline Repeat operation & $117(53.7 \%)$ & $13(65.0 \%)$ & 0.6276 \\
\hline Right lobe or left lobe & $138 / 80$ & $14 / 6$ & 0.5144 \\
\hline Number of tumors & $1(1-5)$ & $1(1-2)$ & 0.5573 \\
\hline Size of largest tumor $[\mathrm{cm}]$ & $2.2(0.7-4.41)$ & $2.7(1.0-5.0)$ & 0.5987 \\
\hline Number of hepatic resections & $1(1-4)$ & $1(1-5)$ & 0.3026 \\
\hline Operative time [min] & $180(40-536)$ & $223(90-560)$ & $0.0148^{*}$ \\
\hline Blood loss [ml] & $50(0-950)$ & $515(40-2030)$ & $<0.0001^{*}$ \\
\hline Positive intraoperative bile leakage & $13(6.0 \%)$ & $2(10.0 \%)$ & 0.4452 \\
\hline
\end{tabular}

B

\begin{tabular}{|lccc|}
\hline Parameter & $P$-value & Odds ratio & $95 \% \mathrm{Cl}$ \\
\hline Hepatitis C viral infection & 0.3213 & 1.917 & $0.532-7.385$ \\
\hline Pathology $(\mathrm{HCC} / \mathrm{ICC})$ & 0.9373 & 1.056 & $0.262-4.099$ \\
\hline Operative time $>195 \mathrm{~min}$ & 0.1766 & 2.625 & $0.655-13.171$ \\
\hline Blood loss $>210 \mathrm{ml}$ & $<0.0001^{*}$ & 12.295 & $3.591-51.773$ \\
\hline
\end{tabular}

${ }^{*} P<0.05$. BMI - body mass index, ICG-R15 - indocyanine green retention rate at $15 \mathrm{~min}, \mathrm{HCC}$ - hepatocellular carcinoma, ICC - intrahepatic cholangiocellular carcinoma. 
hesions. By using these techniques, intraoperative blood loss can be decreased, surgery can be performed safely, and the isolated side of the liver can be kept dry [13].

\section{Conclusions}

Mobilization is easier and a better field of vision can be established during laparoscopic left hepatic lobe tumor resection compared to that obtained with right hepatic lobe tumor resection. In addition, laparoscopic hepatic resection for tumors of the right hepatic lobe can be performed more safely with occlusion of the hepatic inflow of blood, co-axial positioning, maintenance of a triangular formation centered on the laparoscope, and routine placement of an intercostal port for hepatic resection in the suprahepatic segments (segments VII and VIII). However, our study was limited by the small number of patients included in the study and the surgical form was limited to partial hepatic resection, which may have caused several biases. Additional randomized clinical trials and meta-analyses are needed.

\section{Acknowledgments}

We are very grateful to all of the patients who volunteered to join this study.

YI was supported by Mitsui Life Social Welfare Foundation.

\section{Conflict of interest}

The authors declare no conflict of interest.

\section{References}

1. Inoue Y, Hayashi M, Tanaka R, et al. Short-term results of laparoscopic versus open liver resection for liver metastasis from colorectal cancer: a comparative study. Am Surg 2013; 79: 495-501.

2. Nord HJ. Laparoscopy - a historical perspective: are gastroenterologists going to reclaim it? Gastrointest Endosc 2008; 68: 67-8.

3. Ishizawa T, Gumbs AA, Kokudo N, et al. Laparoscopic segmentectomy of the liver: from segment I to VIII. Ann Surg 2012; 256: 959-64.

4. Inoue Y, Asakuma M, Hirokawa F, et al. Single port access for laparoscopic lateral segmentectomy. Videosurgery Miniinv 2017; 12: 357-65.

5. Ban D, Tanabe M, Ito $\mathrm{H}$, et al. A novel difficulty scoring system for laparoscopic liver resection. J Hepatobiliary Pancreat Sci 2014; 21: 745-53.
6. Inoue $\mathrm{Y}$, Hayashi M, Komeda K, et al. Resection margin with anatomic or nonanatomic hepatectomy for liver metastasis from colorectal cancer. J Gastrointest Surg 2012; 16: 1171-80.

7. Inoue Y, Tanaka R, Komeda K, et al. Fluorescence detection of malignant liver tumors using 5-aminolevulinic acid-mediated photodynamic diagnosis: principles, technique, and clinical experience. World J Surg 2014; 38: 1786-94.

8. International Union Against Cancer (UICC). Sobin LH, Gospodarowicz MK, Wittekind C (eds). TNM Classification of Malignant Tumours. $7^{\text {th }}$ ed. Wiley-Blackwell, New York 2009.

9. Dindo D, Demartines N, Clavien PA. Classification of surgical complications: a new proposal with evaluation in a cohort of 6336 patients and results of a survey. Ann Surg 2004; 240: 205-13.

10. Clavien PA, Barkun J, de Oliveira ML, et al. The Clavien-Dindo classification of surgical complications: five-year experience. Ann Surg 2009; 250: 187-96.

11. Mangram AJ, Horan TC, Pearson ML, et al. Guideline for prevention of surgical site infection, 1999. Centers for Disease Control and Prevention (CDC) Hospital Infection Control Practices Advisory Committee. Am J Infect Control 1999; 27: 97-132.

12. Uchiyama K, Ueno M, Ozawa S, et al. Half clamping of the infrahepatic inferior vena cava reduces bleeding during a hepatectomy by decreasing the central venous pressure. Langenbecks Arch Surg 2009; 394: 243-7.

13. Pringle $\mathrm{JH}$. Notes on the arrest of hepatic hemorrhage due to trauma. Ann Surg 1908; 48: 541-9.

Received: 26.02.2018, accepted: 28.03.2018. 